IJHS, e-ISSN 2597-4718, p-ISSN 2597-470X, Vol. 2, No. 1, September 2018, pp. 1-9

International Journal of Humanity Studies

IJHS

International Journal of Humanity Studies

http://e-journal.usd.ac.id/index.php/IJHS

Sanata Dharma University, Yogyakarta, Indonesia

\title{
THE PORTRAYAL OF AN AFGHAN WIFE IN ÅSNE SEIERSTAD'S THE BOOKSELLER OF KABUL: STYLISTIC ANALYSIS
}

\author{
Arina Isti'anah \\ Sanata Dharma University, Indonesia \\ arina@usd.ac.id \\ DOI: https://doi.org/10.24071/ijhs.2018.020101 \\ Received 7 July 2018; revised 13 August 2018; accepted 23 August 2018
}

\begin{abstract}
In the grammatical level of analysis, transitivity is one of the choices. The role of verb in a clause determines its process and participants, and thus imply particular meanings. This research took two chapters as the research data taken from a novel by Åsne Seierstad entitled The Bookseller of Kabul. Talking about literature about Afghanistan society, what attracts this research is the Afghan character named Sharifa. The research found that Seierstad employed various types of processes, participants and circumstances to describe Sharifa. First, the use of Actor and of material process aims at portraying the responsibility of an Afghan wife in spite of the sorrow seen from the mental process with Sharifa as the Senser. The use of relational process with Sharifa as the Carrier is to attach her to particular character, both physical and psychological states. In sum, the novel portrays the Afghan wife as a submissive, yet devoted character.
\end{abstract}

Keywords: Afghan's wife, stylistics, transitivity

\section{Introduction}

Men and women have different roles in a particular society, especially in a patriarchal one. One of which is Afghanistan in which father has the most powerful role in a family. In spite of the powerless figure in the society, women in Afghanistan have been stereotyped as submissive and in need of liberation (Andrews, 2016). In The Bookseller of Kabul, a novel written by Åsne Seierstad, the portrayal of patriarchal family is obviously found in the narration. Sultan Khan, the eldest son of Bibi Gul, is a successful bookseller in Kabul who has two wives, Sharifa and Sonya. The novel starts the narration by discussing Sultan Khan's second marriage to a sixteen-year-old girl named Sonya. The character of Sharifa, the first wife, is narrated in particular language choice, so this research focuses on the portrayal of the Afghan wife.

In Afghanistan, girls are raised to be good mothers and tolerant housewives. Therefore, education is ignored (Rahimi, 1991, p. 6). The tolerance is shown in the novel, represented by Sharifa. She has to accept the fact that her husband, Sultan Khan, has married to Sonya without her permission. Young girls are common to marry at the ages of 13 and 16. Young girls had no right to choose 
their future husbands, or question their engagement, arranged by their parents (Rahimi, 1991, p. 6). She has nothing to do with her husband's choice, yet silence and obedience. The representation of Sharifa to represent an Afghan wife provokes this present research.

The observation of literary works by means of linguistic study is offered by stylistics. Quirk mentions that stylistics is "something like a revolution in the relation between linguistic and literary studies" (Ravassat \& Culpeper, 2011, p. 2 ). The linguistic description of the language in literary works provide the reliable proof on how particular meanings are interpreted. By doing so, the personal assumption can be avoided. Ufot adds that "stylistics is the study of the language of literature which employs the various tools of linguistic analysis" (Ufot, 2013, p.101). In this research, the grammatical choice in the literary work is observed by means of transitivity analysis proposed by Halliday.

In analyzing a novel, its components are categorized into three: chapters relating to each other and the novel as a whole, paragraphing relating to the chapter, sentences relating to the paragraph, and words and phrases relating to sentences (Beard, 2004, p. 15). This research takes two chapters which represent Sharifa. Furthermore, the grammatical choice in the chapters is explained further. By analyzing the grammar of language, this research refers to Halliday's systemic functional grammar (SFG) which looks at language as a 'social semiotic' which directs attention to the communicative and socially expressive functions of language (Leech \& Short, 2007, p. 4).

Lock mentions three types of meanings within grammatical structures: experiential, interpersonal and textual meanings $(1996$, p.8). In the experiential meaning, grammar is used to identify how messages are packed in particular processes seen through transitivity analysis. Transitivity system "acknowledges that the verbal element is the core of the clause, and that the choice of lexical verb itself is somehow crucial to the rest of the choices in the clause" (Jeffries \& Mclntyre, 2010, p. 72). Transitivity system is a grammatical system dealing with different processes found in the language and structures (Song, 2013). Simpson summarizes the four processes in transitivity analysis: material, verbalization, mental and relational (Jeffries \& Mclntyre, Stylistics, 2010, p. 73).

Transitivity is a grammatical system which deals with some types of process, consisting of participants and circumstances, found in language and its structures (Song, 2013). There are three main process types in Hallidian system: material, mental and relational. Material process reflects the outer experience, the process of the external world, such as in "you produce so much money". On the other hand, mental process reflects the inner experience of an emotion, such as in "I was fascinated by it". Relational process is about identifying and classifying. The example of relational process is "Every fourth African is a Nigerian" (Halliday \& Matthiessen, 2004, p.170).

The next process is behavioral process, the borderline of material and mental processes, which refers to "the outer manifestations of inner workings, the acting out of processes of consciousness and psychological states". The example is "People are laughing". The following process is verbal process, which represents the symbolic relationships constructed in human consciousness and enacted in the form of language, like saying and meaning" The example is "we say". The existential process refers to the process of "to be", to exist or to happen (Halliday 
\& Matthiessen, 2004, p.171). The example is "Today there's Christmas in the south". The table below summarizes the processes, meanings and participants by Halliday.

Table 1. The Six Processes Proposed by Halliday.

\begin{tabular}{cccc}
\hline No & Process Types & Meanings & Participants \\
\hline 1 & Material & Doing, happening & Actor-Goal \\
2 & Mental & Feeling, thinking & Senser-Phenomenon \\
3 & Relational & Classifying & Carrier-Attribute \\
& & Identifying & Token-Value \\
4 & Verbal & Saying & Sayer-Verbiage-Receiver \\
5 & Behavioral & Behaving & Behaver \\
6 & Existential & Being & Existent \\
\hline
\end{tabular}

The employment of SFG to analyze literary works has attracted scholars. A transitivity analysis researching the main character in Hoa Pham's "Heroic Mother" proves that transitivity is able to find out the significance of verb choice in representing the character role. The research gives the general view of the story that elderly like talking about their past memories and victories to educate the young generations. The analysis figured out that the main character is suffered from loneliness, boredom, and inconsideration from her family. Seen from the transitivity processes, the main character is described to live with sorrow and victories, also ignored by the youngster. The verbs are concluded to represent the main character's devoting energy, youth and life to the country's independence (Nguyen, 2012).

The representation of women in Pakistani is researched through transitivity choice made by a Pakistani woman author. The research takes a novel written in Urdu, the national language in Pakistan, in a consideration that it represents the true Pakistani society. From the observation, the employment of mental and material processes in the story reveals that the woman author is still influenced by the society. Women are represented as negative and oppressors. The narration shows that women are passive and dependent on men. The actions denoted to women are reactions of men's actions (Shah, Zahid, Shakir, \& Rafique, 2014).

Similar to previous studies mentioned above, the present research takes how the narrator describes an Afghan wife represented by Sharifa. The first objective is to figure out the linguistic features used by the narrator to describe the Afghan wife. The second objective is to conclude how an Afghan wife is portrayed in the novel. By doing this research, it is expected that studies on literature by means of stylistics can be studied further by scholars. It also invites future researchers to compare the portrayal of men and women in Afghanistan seen in literary works.

\section{Method}

This research employs stylistics as its approach since it provides the linguists to observe literary texts. In stylistics, there are some language levels to observe, one of which is grammatical level. In this level, the researcher employs Halliday's transitivity analysis under Systemic Functional Grammar point of view. Stylistics provides the systematic study of language description of literary works. It is claimed that stylistics shows the process of how language is utilized to criticize literary works (Widdowson, 2013). The study will not only display the language 
feature description, but also figure out the effects resulted from the choice of words. In stylistics, transitivity analysis is believed to figure out the effects of particular choice. In this research, the effects are the character of an Afghan wife portrayed in the novel.

The main data were taken from a collection of novel entitled The Bookseller of Kabul by Åsne Seierstad. The novel was published by Back Bay Books in New York. The novel contains of 19 chapters. Of those chapters, the researcher selected the ones presenting the role of women. In other words, the extracts of the novel were purposively selected in the way they present an Afghan wife. "The Proposal" and "Crime and Punishment" were the two chapters involving Sharifa the most in the description.

The data were analyzed in some steps. First, the researcher selected particular chapters of the novel which describe the woman characters the most. Second, the researcher sorted the narrator's utterances in describing the Afgan wife character and categorize each utterance using transitivity analysis. Third, the researcher summarized the process types of transitivity which represented the character. Fourth, the researcher interpreted the roles of the Afghan wife in the story by referring to the linguistic features used to describe the character.

\section{Findings and Discussion}

From the observation done by the researcher, Sharifa is represented in various processes, participants and circumstances. The most used process employed is material process with Sharifa as the Actor. The material verbs relating to households mark the process. The relational process with Sharifa as the Carrier is also found in the novel. It is to describe Sharifa's physical state and status. The next process found is mental process marked by cognition verb such as think and know. The last process is behavioural process, marked by the verb sigh. The paragraphs below display how Seierstad portrays Sharifa in the novel.

The extract below is taken from the first chapter of the novel, "The Proposal". In the beginning of the novel, Seierstad tells about the plan Sultan Khan has made to propose a young girl to be his second wife. This is the power of man in Afghanistan to arrange his marriage. In Islam, men are allowed to have more than one wife. It is also represented in "The Proposal". However, this research is more interested in describing how the first wife, Sharifa, is represented in the novel. Seierstad chooses various processes to represent Sharifa. The extract below is the example.

Sharifa [Carrier] was getting old [Attribute]. Like Sultan [Circumstance of manner], she [Carrier] was a few years over fifty [Attribute]. She [Actor] had borne him [Recipient] three sons and a daughter [Goal]. The time had come for a man of Sultan's standing to find a new wife. (p.4)

The first sentence above is chosen in the relational process. Relational process shows that relationship is a set up between two concepts: an object (Carrier) and a quality (Attribute) (Thompson, 2014, p.101). The Linking Verb get marks the process. Sharifa is the Carrier who is attached to the Attribute old. Here, Seierstad introduces the physical state of Sharifa to the readers. However, the circumstance of manner found in the beginning of the second sentence emphasizes that Sultan Khan is also in the same state as Sharifa. The relational process in the second sentence is the further description of how old Sharifa is. The 
next process found in the extract above is material process. The material verb borne is chosen in the novel to tell the readers that Sharifa has given four children to the husband, Sultan Khan represented as the Recipient. That explanation is to explain the reason of Sulan's choosing another woman to be his wife. It is not because of Sharifa's inability to give him children, but the husband's power and prestige to choose another woman to be his second wife. In the last sentence of the extract above, Seierstad also notices that men over fifty are common to find another woman.

What is interesting in the first chapter of the novel is that Sultan Khan did not tell his wife and family that he would propose a sixteen-year-old girl named Sonya. He managed the proposal himself. This condition makes his wife and the family shocked. Usually, the mother and sisters would arrange a marriage of the man in the family. However, that situation is not found in Sultan Khan's choice. The extract below shows the response of Sharifa, the wife.

Sultan went home to inform his family of the news. His wife, Sharifa, his mother, and his sisters [Actor] were seated around a dish of rice and spinach [Circumstance of place]. Sharifa [Senser] thought he was joking [Phenomenon] and laughed and cracked some jokes [Goal] in return [Circumstance of manner]. (p.7)

The fact that Sultan Khan was about to marry a young woman was never imagined by Sharifa. There are three processes found in the above extract. First is material process marked by the verb seated which involves physical action (Thompson, 2014). The second is mental process marked by the verb thought. It refers to the participant's consciousness about the news brought by her husband. That is, why Sharifa responded it by laughing as a Behaver. This process involves both material and mental. The following response given by Sharifa is crack some jokes, a material process, showing an action by Sharifa to deny the fact she just found out.

When the engagement day comes, Sultan asked Sharifa, his mother and sisters to attend the event. He intends to show Sonya's family that the wife and the whole family supports him. As a wife, Sharifa is represented in a material process as the Actor who conducts particular action for the sake of her husband.

Twenty days after the proposal of marriage the solemn engagement ritual took place. Sharifa [Actor] pulled herself [Goal] together [Circumstance of manner] and put on a brave face [Goal]. (p.8)

The material verb in the above extract is done by Sharifa in a situation that forced her to do so. The Actor and Goal shown above refer to Sharifa. It reveals Sharifa's submission to her husband. The employment of the second Goal a brave face actually signals Sharifa's fear to face the reality. In the material process mentioned in the above extract, Sharifa is the doer or Actor. The noun phrases herself and a brave face in the extract above are regarded as Goals, meaning the participants that something was done to it (Fontaine, 2013, p.74). The choice of words by the author in the extract above signifies that Sharifa intends to make some physical actions for the sake of his husband. The Goals mentioned in the extract are for the husband and family's name.

To accept the fact that her husband is about to marry a young girl upsets Sharifa. Eventually Sharifa cannot keep her disappointment to her husband when the wedding day comes. The extract below is the proof. 
Sharifa [Carrier] was inconsolable [Attribute]. What really rankled was the fact that the man had picked an illiterate, someone who had not even completed nursery school. She, Sharifa [Carrier], was a qualified Persian language teacher [Attribute]. "What has she got that I haven't got?" [Verbiage] she [Sayer] sobbed. (p.7)

The first sentence in the above extract takes Sharifa as the Carrier and inconsolable as the Attribute. The process is relational, meaning that it attributes some kind of quality to a participant entity (Fontaine, 2013, p.76). Sharifa is the noun attached to adjective inconsolable as the Attribute. As a wife, Seierstad portrays Sharifa as a sad wife having to accept the fact that her husband picked someone who does not belong to the same class as her. The extract above obviously portrays that Sharifa is an educated person. The third sentence takes Sharifa as a Carrier and a qualified Persian language teacher as Attribute. Since the Attribute is in the form of noun group, it means that Sharifa is referred to the class of entity which the Carrier belongs.

With the backup of the family, Sharifa shows her action by refusing to attend the wedding ceremony. It is shown in the following datum.

The wedding took place two months after the engagement, on the day of the

Muslim New Year's Eve. This time [Circumstance of time] Sharifa [Actor] refused to attend [Goal]. (p.8)

The circumstance of time above refers to the wedding day of Sultan's marriage to Sonya. The verb refused in the above extract takes Sharifa as the Actor. This becomes the climax of Sharifa's rebel to her husband. After her silence and obedience shown in the engagement day, Sharifa is eager to reject her husband's request to attend the wedding.

The first chapter of the novel taken as the sample discussed above reveals that in one hand, Sharifa is portrayed as a submissive wife. On the other hand, Sharifa is portrayed as an educated woman. The education she has influences her action not to attend her husband's wedding. Despite her internal conflict, Sharifa is also devoted to her family. She chooses not to divorce from Sultan, but stay for the sake of the family dignity.

In the chapter "Crime and Punishment", Seierstad tells the readers more about the relationship between Sharifa and Sonya. Sharifa then decides to make peace with the condition she faces. The following extract is taken for the second chapter of the data.

Sharifa [Actor] sweeps the floors [Goal], washes curtains [Goal], busies herself [Goal] with the perpetual dusting [Circumstance of manner], sits down, sighs, sheds a few tears [Goal]. (p.24)

Sharifa [Actor] cooked, served, washed, and make the beds [Goal]. (p.25)

The above sentences are represented in material process with Sharifa as the Actor. The underlined words above mark material verbs, representing actions the Actor does. Those verbs signify the house chores done by the wife. It is the wife's responsibility to manage things at home. The verb shed in the first sentence above shows Shafira's sadness of being the first wife who still takes responsibility of doing chores.

What is dilemmatic for Sharifa is that she has to perform her responsibility as a good wife instead of getting divorce from Sultan Khan. The data below show material process representing Sharifa. 
She [Actor] swallowed her pride [Goal] and appeared the model wife. (p.25) Sharifa tried to chirp like a fussing mother hen. She [Actor] took on the heaviest chores [Goal] and little by little [Circumstance of manner] taught Sonya [Recipient] how to make Sultan's favorite dish, showed her how he liked his clothes organized, the temperature of the water he washed in, and other details that a wife should know about her husband [Goal]. (p.26)

The verbs swallowed is a material verb with her pride as the Goal. It is the constituent which the action is directed to. In the following sentence, the verbs tried, took and taught are also material verbs with Sharifa as the Actor. She is the constituent who conducts the actions, including teaching Sonya how to serve Sultan, their husband.

The actions done by Sharifa above results in some feelings experienced by Sharifa presented in mental process. Below are the examples.

She [Senser] knows that Sultan will turn up one of these days [Phenomenon], but he can never be bothered to tell her exactly when he is leaving Kabul, so Sharifa [Senser] expects him home [Phenomenon] every hour for days on end [Circumstance of time].

The first process found above is mental process, referring to something that goes on in the internal world of mind (Thompson, 2014, p.97). The participants in the mental process above are Senser and Phenomenon. Senser is the participant which senses, while Phenonemon is the participant which is being sensed (Fontaine, 2013, p.75). In the above extract, she representing Sharifa is the Senser. It takes a Phenomenon in the form of a noun clause that Sultan will turn up one of these days. Mental process in that sentence is marked by the verb knows categorized as cognitive process. Here, Sharifa involves her consciousness when she is waiting for her husband. Beside cognitive mental process, Sharifa is also represented in desiderative mental process marked by the verb expects. This kind of process shows Senser's wish. The extract above shows Sharifa's awareness and expectation to her husband.

Though Sharifa does not decide to divorce from Sultan, she cannot deny her feeling of betrayal. Below is the datum in mental process.

Sometimes she [Senser] hates him [Phenomenon] for having ruined her life, taken away her children, shamed her in the eyes of the world [Circumstance of reason]. (p.24)

The verb hates in the above sentence is categorized as emotive mental process. It refers to the Senser's emotion to the Phenomenon. Since the verb shows the process of feeling, the mental process in the above extract is categorized as emotive or reactive mental process (Thompson, 2014, p.99). It is clearly seen that the Senser is Sharifa and the Phenomenon is him, referring to Sultan Khan. Shafira blames her husband for the material actions he has done to her: ruining her life, taking away the children and shaming her in the eyes of the world. The actions mentioned previously creates emotion to Sharifa.

Another process to represent Sharifa is relational process. The sentences below are the examples.

Sharifa, the pensioned-off wife, [Actor] is waiting in Peshawar [Circumstance of place]. She [Carrier] has no peace [Attribute]. She knows that Sultan will turn up one of these days... (p.23) 
The relational process in the above extract is shown by the verb has. Thus, the process is categorized as possessive relational process. Sharifa, represented in pronoun she is the Possessor and no peace is Possessed. This kind of process is to attach Sharifa with no peace. As a wife, she does not possess that kind of abstract thing. It is explained by the first sentence above since Sharifa is the Actor who conducts the material verb wait.

The other relational process representing Sharifa is displayed in the following sentence. (p.25)

She [Carrier] swallowed her pride and appeared the model wife [Attribute].

The linking verb appeared functions to attach Sharifa as the Carrier to the Attribute the model wife. Despite peace that she does not get, Sharifa is attached as the model wife. She still takes care of households and gives examples to Sonya how to serve the husband.

The next process to characterize Sharifa is behavioral process. It refers to a "borderline area between mental processes and material processes" (Downing \& Locke, 2006, p. 151).

Sharifa [Behaver] sighs. She [Senser] thinks of the punishment that befell her neighbor Jamila [Phenomenon]. (p. 34)

Shafira [Behaver] sighs. Jamilla committed a serious crime, but more from ignorance than a wicked heart. (p.36)

The verb sigh marks the behavioral process. The mental process refers to Sharifa's feeling towards her neighbor, Jamilla. What makes Sharifa sigh is the punishment given to Jamila, her neighbor who just died. Jamilla is a newly-wed whose husband left for work. During that time, her husband's brother found a man visiting Jamilla by finding out things belonging to the suspect. Since the family is so shamed of the situation, Jamilla's mother decides to ask his sons to kill Jamilla. It happens since a woman having an affair with another man is a disgrace to the family.

From the elaboration above, material verbs designated to Shafira is used by Seierstad to represent the household actions a wife does. Despite the feelings Sharifa has, which are represented in mental verbs, Seierstad portrays Sharifa as a tough woman. The one-sided decision to marry a young girl made by her husband, Sharifa does not have any courage to leave her husband. Disgrace is attached to a divorced woman in Afghanistan. Thus, to maintain the family's dignity, Sharifa chose to stay and even she accepts Sonya, the second wife, eventually.

\section{Conclusion}

Through stylistic analysis, the description of particular character in the story can be objectively and obviously explained. This research supports the previous claim since stylistics takes "a close look at the text and analyses its significant language forms and expressions for the sake of interpretation, it comes very close to practical criticism" (Al Shawa, 2015, p.125). This research interprets that Sharifa as an Afghan wife is portrayed as a submissive, yet devoted wife. She can solve the internal conflict she has in order to maintain the family's pride and dignity. This research suggests future scholars to compare the portrayal of the husband and conclude how the choice of wordings in the novel can create different meanings of particular literary work. 


\section{References}

Andrews, A. (2016). (Re)Defining Afghan women characters as modern archetypes using Khaled Hosseini's a thousand splendid suns and asne seierstad's the bookseller of kabul. ProQuest LLC.

Beard, A. (2004). The language of literature. New York: Routledge.

Downing, A., \& Locke, P. (2006). English grammar: A university course. London: Routledge.

Fontaine, L. (2013). Analysing English grammar: A systemic functional introduction. Cambridge: Cambridge University Press.

Halliday, M., \& Matthiessen, M. (2004). An introduction to functional grammar. London: Horder Arnold.

Jeffries, L., \& Mclntyre, D. (2010). Stylistics. Cambridge: Cambridge University Press.

Leech, G., \& Short, M. (2007). Style in fiction: A linguistic introduction to English fictional prose. Harlow: Pearson.

Nguyen, T. H. (2012). Transitivity analysis of heroic mother by Hoa Pham. International journal of English linguistics, 2(4), 85-100.

Rahimi, W. M. (1991). Status of women: Afghanistan. Bangkok: UNESCO Principal Regional Office for Asia and the Pacific.

Ravassat, M., \& Culpeper, J. (2011). Stylistics and Shakespeare's language: transdisiplinary approaches. New York: Continuum.

Seierstad, Å. (2004). The bookseller of Kabul. New York: Hachette Book Group.

Shah, S. K., Zahid, S., Shakir, A., \& Rafique, S. (2014). Representation of women in Mann O Salwa: A case study through feminist stylistic analysis. Research on humanities and social sciences, 4(7), 90-105.

Shawa, W. (2015). Stylistics analysis of the poem 'To A Skylark' by P.B. Shelley. IOSR journal of humanities and social science. 20(1), 124-137.

Song, Z. (2013). Transitivity analysis of a rose for Emily. Theory and practice in language studies, 3(12), 2291-2295.

Thompson, G. (2014). Introducing functional grammar (3ed). New York: Routledge.

Ufot, B. G. (2013). Phonology and stylistics: A phonoaesthic study of Gray's 'Elegy Written in a Country Churchyard'. English linguistics research, 2(2), 110-125.

Widdowson, H. G. (2013). Stylistics and the teaching of literature. New York: Routledge. 